\title{
Zeitungsabo-Verwaltung auf myFMH
}

\section{Claudia Blackburn}

Leiterin Dienstleistungen und Mitgliedschaft

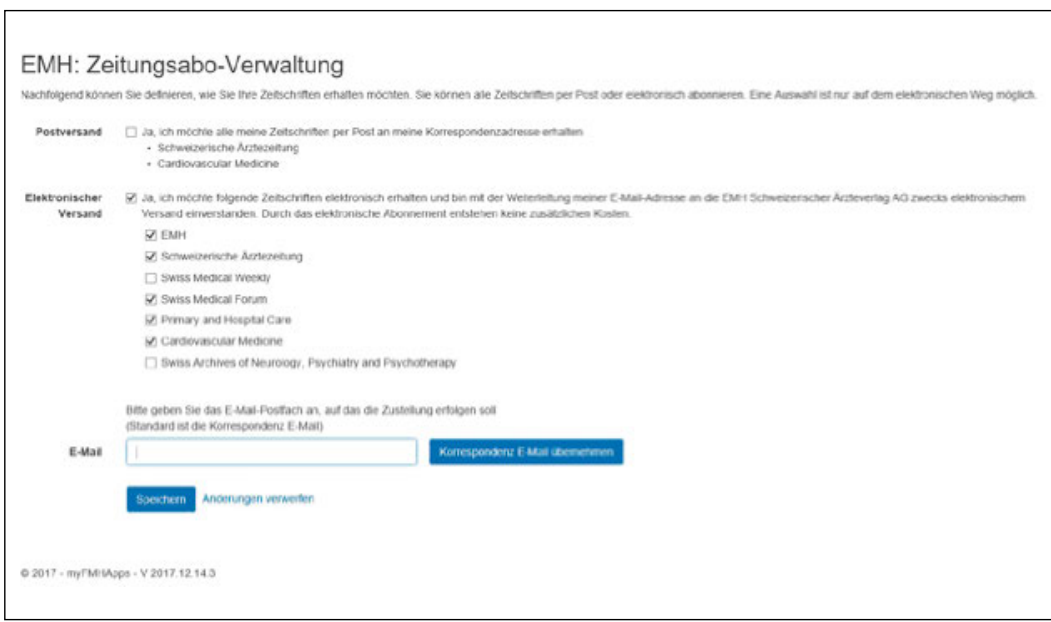

Die FMH bietet ihren Mitgliedern über das Online-Portal myfmh.ch eine neue Dienstleistung. Via Ihren persönlichen Zugang «myFMH» können Sie die Abonnementverwaltung der Zeitschriften des EMH Schweizerischen Ärzteverlags persönlich und ohne Rücksicht auf Bürozeiten steuern. Die neue App (myFMH.ch $\rightarrow$ EMH: Abo-Verwaltung) gibt Ihnen die Möglichkeit, jederzeit selber zu bestimmen, ob Sie ihre Zeitschriften weiterhin in Papierform und/oder im elektronischen Versand empfangen wollen.

\section{Gestion des abonnement
aux revues sur myFMH}

\section{Claudia Blackburn}

Cheffe du Service Administration des membres

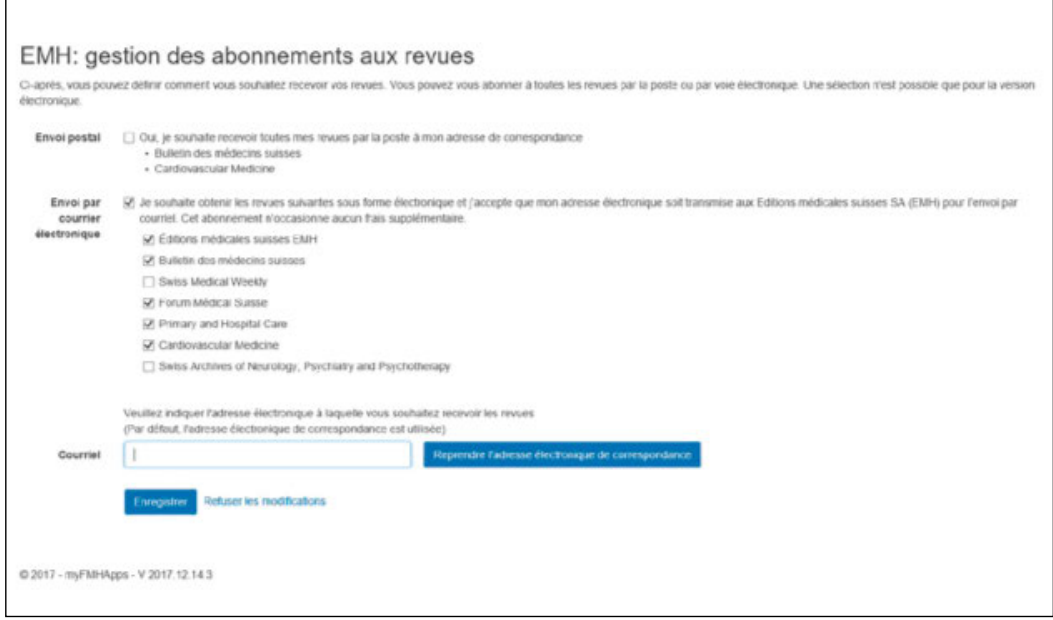

La FMH propose à ses membres un nouveau service par l'intermédiaire de son portail en ligne myfmh.ch. Au moyen de votre accès personnel à myFMH, vous pouvez gérer vos abonnements aux revues des Editions médicales suisses (EMH) même en dehors des heures de bureau. La nouvelle application (myFMH.ch $\rightarrow$ EMH: gestion des abonnements) vous donne la possibilité de décider vous-même en tout temps si vous souhaitez continuer à recevoir vos revues sur papier et/ou les obtenir par voie électronique. 